\title{
Correction to: Whole genome sequencing Mycobacterium tuberculosis directly from sputum identifies more genetic diversity than sequencing from culture
}

\author{
Camus Nimmo ${ }^{1,2^{*}}$ (D) Liam P. Shaw ${ }^{3,4}$, Ronan Doyle ${ }^{1,5}$, Rachel Williams ${ }^{1}$, Kayleen Brien ${ }^{2}$, Carrie Burgess ${ }^{1}$,
} Judith Breuer ${ }^{1}$, Francois Balloux ${ }^{3}$ and Alexander S. Pym²

\section{Correction to: BMC Genomics (2019) 20:389}

DOI: $10.1186 / \mathrm{s} 12864-019-5782-2$

Following the publication of this article [1], the authors reported that one of the authors' names was typeset incorrectly in the authorship list.

In this Correction article the incorrect and correct author name are shown. The original publication of this article has been corrected.

Originally the author name was published as:

- Rona Doyle

The correct author name is:

- Ronan Doyle

The publisher apologizes to the authors and readers for any inconvenience caused by this error.

\section{Author details}

'Division of Infection and Immunity, University College London, London WC1E 6BT, UK. ${ }^{2}$ Africa Health Research Institute, Durban, South Africa. ${ }^{3} \mathrm{UCL}$ Genetics Institute, University College London, London WC1E 6BT, UK.

${ }^{4}$ Nuffield Department of Clinical Medicine, Oxford University, Oxford OX3 $7 \mathrm{BN}$, UK. ${ }^{5}$ Clinical Research Department, London School of Hygiene and Tropical Medicine, London WC1E 7HT, UK.
Received: 24 May 2019 Accepted: 24 May 2019

Published online: 29 May 2019

\section{Reference}

1. Nimmo C, et al. Whole genome sequencing Mycobacterium tuberculosis directly from sputum identifies more genetic diversity than sequencing from culture. BMC Genomics. 2019;20:389 https://doi.org/10.1186/s12864019-5782-2.

* Correspondence: c.nimmo.04@cantab.net

${ }^{1}$ Division of Infection and Immunity, University College London, London WC1E 6BT, UK

${ }^{2}$ Africa Health Research Institute, Durban, South Africa

Full list of author information is available at the end of the article

(c) The Author(s). 2019 Open Access This article is distributed under the terms of the Creative Commons Attribution 4.0 International License (http://creativecommons.org/licenses/by/4.0/), which permits unrestricted use, distribution, and reproduction in any medium, provided you give appropriate credit to the original author(s) and the source, provide a link to the Creative Commons license, and indicate if changes were made. The Creative Commons Public Domain Dedication waiver (http://creativecommons.org/publicdomain/zero/1.0/) applies to the data made available in this article, unless otherwise stated. 